\title{
Avaliação do comportamento de vigas de bambu laminado colado submetidas à flexão
}

\author{
Behavior analysis of glued laminated bamboo beam under \\ bending
}

\begin{tabular}{|c|c|}
\hline & $\begin{array}{l}\text { Douglas Mateus de Lima } \\
\text { Mariana Mendes Amorim } \\
\text { Humberto Correia Lima Júnior } \\
\text { Normando Perazzo Barbosa } \\
\text { Fábio Luiz Wilrich }\end{array}$ \\
\hline $\begin{array}{r}\text { Douglas Mateus de Lima } \\
\text { hiversidade Federal de Pernambuco } \\
\text { Caruaru - PE - Brasil }\end{array}$ & $\begin{array}{l}\text { Resumo } \\
\text { presente trabalho apresenta e discute um estudo experimental de } \\
\text { vigas de bambu laminado colado (BLC). Utilizaram-se ripas } \\
\text { provenientes do bambu Dendrocalamus giganteus para a confecção de } \\
\text { vigas de seção transversal retangular, as quais foram preparadas com } \\
\text { quatro diferentes disposições de nós e de emendas. Dois tipos de adesivos foram } \\
\text { utilizados: um à base de resorcinol-formaldeído, e outro à base de poliacetato de } \\
\text { vinila (PVA). As vigas foram ensaiadas à flexão por meio de quatro pontos de } \\
\text { carga. Os resultados foram comparados com vigas de referências, de dimensões } \\
\text { similares, confeccionadas com duas espécies de madeiras de reflorestamento: } \\
\text { Araucaria angustifolia e Eucalyptus grandis. O modo de ruptura das vigas foi em } \\
\text { função da disposição dos nós e do tipo de emendas, além do tipo de adesivo } \\
\text { utilizado. Curvas de carga vs. deslocamento são apresentadas, e foi observado que } \\
\text { as vigas confeccionadas com adesivo à base de resorcinol-formaldeído } \\
\text { apresentaram desempenho estrutural superior ao das vigas confeccionadas com }\end{array}$ \\
\hline $\begin{array}{r}\text { Mariana Mendes Amorim } \\
\text { Universidade Federal de Pernambuco } \\
\text { Caruaru - PE - Brasil }\end{array}$ & $\begin{array}{l}\text { Palavras-chave: Bambu. Adesivo. Viga. } \\
\text { Abstract }\end{array}$ \\
\hline $\begin{array}{r}\text { Humberto Correia Lima Júnior } \\
\text { Universidade Federal de Pernambuco } \\
\text { Caruaru - PE - Brasil }\end{array}$ & $\begin{array}{l}\text { This paper presents and discusses the experimental analyses of glued laminated } \\
\text { bamboo (GLB) beams. The mechanical behavior of rectangular cross-section } \\
\text { composite beams made with Dendrocalamus giganteus bamboo strips was studied. }\end{array}$ \\
\hline $\begin{array}{r}\text { Normando Perazzo Barbosa } \\
\text { Universidade Federal da Paraíba } \\
\text { João Pessoa - PB - Brasil } \\
\text { Fábio Luiz Wilrich } \\
\text { ITAIPU Binacional } \\
\text { Foz do Iguaçu - PR Brasil }\end{array}$ & $\begin{array}{l}\text { Four different positions of the bamboo layer nodes and joins and two glue types } \\
\text { (resorcinol-formaldehyde and polyvinyl acetate) were investigated. The results } \\
\text { were compared with reference beams made with reforesting wood: Araucaria } \\
\text { angustifolia and Eucalyptus grandis. The beam failure mode depended on the } \\
\text { node and join position and the glue type. Curves of load vs. displacement are } \\
\text { presented and it was observed that the beams made with resorcinol-formaldehyde } \\
\text { glue presented structural behavior superior than those made with polyvinyl } \\
\text { acetate and the reference ones. }\end{array}$ \\
\hline $\begin{array}{r}\text { Recebido em 18/04/13 } \\
\text { Aceito em 22/10/13 }\end{array}$ & \\
\hline
\end{tabular}

LIMA, D. M. de; AMORIM, M. M.; LIMA JÚNIOR, H. C.; BARBOSA, N. P.; WILRICH, F. L. Avaliação do comportamento de 15 vigas de bambu laminado colado submetidas à flexão. Ambiente Construído, Porto Alegre, v. 14, n. 1, p. 15-27, jan./mar. 2014.

ISSN 1678-8621 Associação Nacional de Tecnologia do Ambiente Construído. 


\section{Introdução}

O âmbito ecológico é um assunto em grande discussão na atualidade e tem incentivado a procura por materiais alternativos, visando à preservação do meio ambiente e à qualidade de vida do homem. O bambu é um material vegetal cujas propriedades mecânicas indicam grande potencial a ser explorado pela engenharia. A planta apresenta longos colmos, ocos no interior, os quais são fechados a intervalos mais ou menos regulares por um diafragma, nas regiões dos nós; suas paredes têm excelente resistência à tração e à compressão, comparáveis às mais nobres madeiras; ressalta-se, ainda, seu baixo peso específico, da ordem de 7,7 kN.m ${ }^{-3}$ (LIMA, 2013). Apesar das formidáveis propriedades físico-mecânicas, o bambu tem sido pouco utilizado como material na indústria da construção civil, devido, basicamente, aos seguintes fatores: sua configuração geométrica impossibilita a confecção de peças estruturais usuais, como vigas e pilares de seções transversais retangulares; e sua baixa resistência ao cisalhamento não permite a cravação de pinos, tornando difícil o projeto de estruturas de maior porte, em que se necessite de emendas ou ligações (MESQUITA et al., 2006). Adicionalmente, o bambu sofre ataque de agentes físicos, químicos e biológicos, que o deterioram, principalmente devido à presença de polímeros de amido nas células parenquimáticas do bambu. Como o nível de ataque do colmo de bambu está diretamente relacionado a seu teor de amido, a espécie Dendrocalamus giganteus, escolhida neste estudo, não é tão susceptível ao inseto Dinoderus minutus (conhecido por caruncho ou broca do bambu), pois apresenta baixo teor de amido em sua composição quando comparada com outras espécies de bambu.

Nos últimos anos, com a preocupação global de preservação ambiental, as indústrias orientais de móveis e de papel têm investido em tecnologia para o aproveitamento mais racional do bambu. Entre tais indústrias, destacam-se as de piso laminado de bambu, que atualmente produzem, em escala industrial, pisos laminados de alto padrão de acabamento. Analisando-se esse processo industrial de laminação do bambu, juntamente com a metodologia aplicada à madeira laminada colada (BONO, 1996), observa-se que esses processos podem ser agrupados e aplicados na fabricação de peças estruturais de bambu laminado colado (BLC). A tecnologia do bambu laminado colado basicamente elimina os problemas de cisalhamento e de geometria discutidos anteriormente, permitindo que esse material tenha utilização mais racional na engenharia estrutural (LIMA JÚNIOR; DIAS, 2001).
Nesse contexto, observa-se que um elemento estrutural simples, no qual se pode utilizar a técnica descrita de forma relativamente simples, são as vigas de BLC, que constituem um produto estrutural formado pela sobreposição de lâminas de bambu coladas com adesivos e submetidas à pressão. A mecânica estrutural desses elementos é similar a das vigas fabricadas com madeira laminada colada (MLC), em cuja análise devem ser consideradas as tensões normais de flexão e as de cisalhamento (principalmente na linha de colagem).

A ausência de norma específica para execução de ensaios de peças de BLC gera dificuldade de padronização dos procedimentos de ensaio e dificuldade de comparação de resultados entre pesquisadores. Dessa forma, resolveu-se utilizar a NBR 7190 (ABNT, 1997) como base dos procedimentos de análise deste trabalho, realizando-se pequenas adaptações necessárias às especificidades do BLC. A referida norma estabelece que as peças de madeira laminadas coladas devam ser constituídas por lâminas de madeira de primeira categoria com espessuras não superiores a $30 \mathrm{~mm}$, coladas com adesivo à prova d'água, à base de fenol-formaldeído sob pressão, em processo industrial adequado que solidarize permanentemente o sistema. Adicionalmente, a direção do carregamento (plano de atuação das cargas) pode ser paralela ou perpendicular ao plano médio das lâminas.

As emendas em vigas laminadas coladas podem ser executadas segundo os modos expostos na Figura 1. Tais emendas são dispostas espaçadamente ao longo da peça (Figura 1e). A NBR 7190 (1997) estabelece que em lâminas adjacentes, de espessura t, suas emendas devam estar afastadas entre si por uma distância maior ou igual a $25 \mathrm{t}$ ou à altura $\mathrm{h}$ da viga. Além disso, as emendas contidas em um comprimento igual à altura da viga devem ser consideradas como pertencentes à mesma seção resistente.

As lâminas emendadas apresentam sua seção resistente reduzida, em função do tipo de junção utilizada, conforme a Equação 1:

$A_{\text {red }}=a_{r} \cdot A_{e f}$

Eq. 1

Na qual:

$A_{\text {red }}$ é a área reduzida da seção transversal da lâmina em análise;

$A_{e f}$ é a área efetiva da lâmina sem a consideração da emenda; e

$\alpha_{r}$ é o coeficiente de redução, que é função do tipo de emenda.

16 Lima, D. M. de; Amorim, M. M.; Lima Júnior, H. C.; Barbosa, N. P.; Wilrich, F. L. 
Sendo adotados os seguintes valores:

(a) emendas dentadas (finger joints): $\alpha_{r}=0,9$;

(b) emendas em cunha (biseladas) com inclinação de 1:10: $\alpha_{r}=0,85$; e

(c) emendas de topo: $\alpha_{r}=0,0$.

Segundo Pfeil e Pfeil (2003), o tipo de adesivo e a técnica de colagem, assim como as características das lâminas (de madeira ou, no caso deste estudo, de bambu), são fundamentais para a durabilidade da peça laminada colada. A colagem é realizada sob pressão, que pode variar entre 0,7 e $1,5 \mathrm{MPa}$, sendo o nível de pressão compatível com a rigidez do material prensado. A dosagem de cola utilizada no processo é de aproximadamente $250 \mathrm{~g} / \mathrm{m}^{2}$. Os produtos estruturais industrializados de laminados colados devem ser fabricados sob rigoroso controle de qualidade, para garantir as características mecânicas e de durabilidade. Devido à distribuição das lâminas na peça laminada colada, elementos estruturais fabricados mediante esse método resultam mais homogêneos do que aqueles feitos com madeira serrada. Os laminados colados permitem a execução de peças de grandes dimensões, melhor controle de umidade, prevenção de defeitos resultantes de secagem irregular, seleção de lâminas colocadas em posições referentes ao nível tensão e construção de peças com eixo curvo, o que permite satisfazer necessidades arquitetônicas. No entanto, a desvantagem desse sistema é o elevado preço, devido ao elaborado nível tecnológico (laminação, seleção das lâminas, custo do adesivo, etc.).

\section{Materiais e métodos}

\section{Materiais}

\section{Bambu}

O bambu utilizado neste estudo foi da espécie Dendrocalamus giganteus Munro, obtido no Zoológico Municipal de Cascavel, PR. Os colmos de bambu, com idades entre 4 e 5 anos, apresentavam comprimento médio de $20 \mathrm{~m}$ e comprimento internodal de $40 \mathrm{~cm}$ a $50 \mathrm{~cm}$. Estes foram cortados e deixados secar à sombra, em temperatura ambiente, durante 3 meses; e, posteriormente, foram secos em estufa a $105^{\circ} \mathrm{C}$, até atingir uma umidade entre $6 \%$ e $8 \%$. Após a secagem e divisão diametral com o auxílio de serra circular, os colmos foram serrados em comprimento longitudinal de $150 \mathrm{~cm}$, e, em seguida, foram extraídas ripas de bambu com dimensões nominais de $150 \mathrm{~cm}, 0,73 \mathrm{~cm}$ de espessura e 3,00 cm de largura (Figura $2 \mathrm{a}$ e 2b). As taliscas foram cortadas com serra circular, aplainadas em uma desengrossadeira e lixadas com o auxílio de lixadeira elétrica de três estágios, para a regularização das superfícies e uniformização da espessura das ripas (Figura 2c). No beneficiamento do colmo, para fabricação das ripas, eliminaram-se os diafragmas e, também, uma fina camada externa da parede do colmo, pois tais regiões dos colmos apresentavam superfícies muito lisas, que comprometeriam a penetração e aderência com os adesivos (PEREIRA; BERALDO, 2008). Apesar de ser uma intervenção necessária, as ripas de bambu não foram tratadas contra o ataque de insetos, devido ao tempo diminuto entre o corte e a realização do ensaio, além de eliminar-se o custo correspondente ao tratamento do bambu.

Figura 1 - Detalhe de emendas em lâminas de vigas laminadas
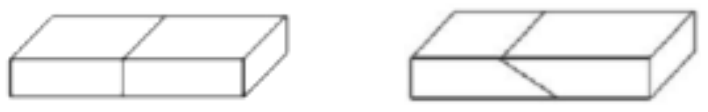

(a) Emenda de topo (b) Emenda biselada

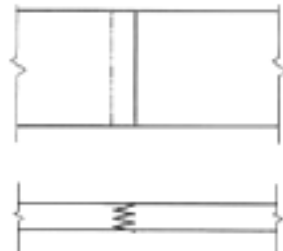

(c) Emenda dentada horizontal
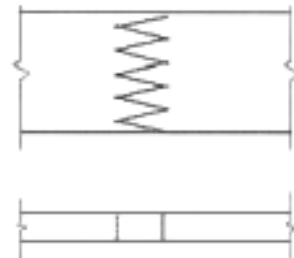

(d) Emenda dentada vertical

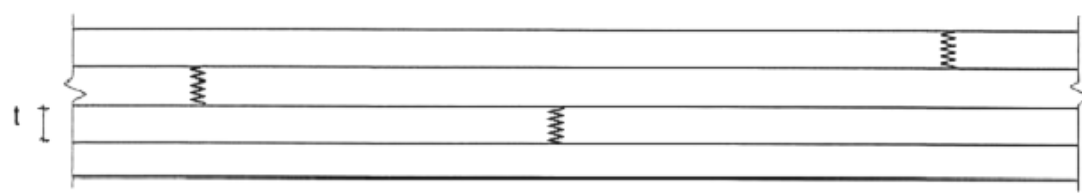

(e) Distribuição das emendas longitudinalmente à viga

Fonte: Pfeil e Pfeil (2003). 
Figura 2 - Detalhes das partes do colmo e das ripas beneficiadas

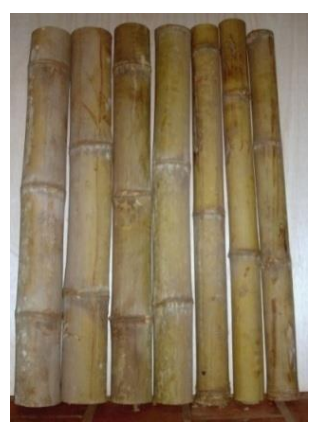

(a) Face externa do colmo

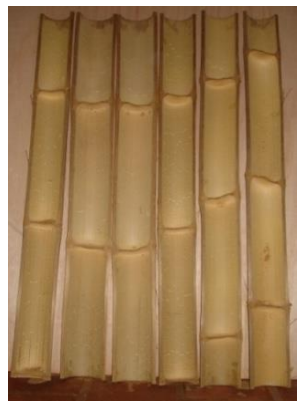

(b) Face interna do colmo

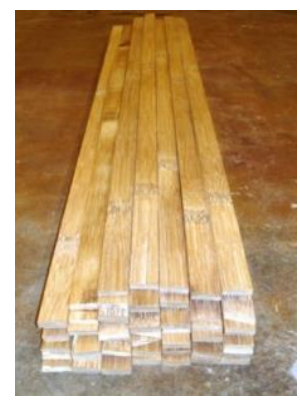

(c) Ripas de bambu após a usinagem

\section{Adesivos}

Os laminados colados de bambu foram fabricados com dois adesivos: um à base de resina fenólica resorcinol-formaldeído, comercialmente conhecido por Cascophen RS-216-M, composto com um misturador endurecedor FM-60-M, utilizado comumente para a fabricação de compensados, estruturas e madeira laminada colada; e outro à base de poliacetato de vinila (PVA), com a denominação comercial de Cascorez, empregado para colagem de peças de madeira em interiores de edificações. De acordo com as especificações fornecidas pelos fabricantes, ambos são indicados para prensagem a frio.

O adesivo Cascophen foi escolhido devido a sua eficaz resistência ao cisalhamento e à tração, além de ser à prova d'água. Apesar de não ser indicado para fins estruturais, o adesivo Cascorez foi escolhido em virtude de apresentar um custo cerca de 20 vezes inferior ao do Cascophen. Para o preparo dos adesivos foram adotadas as recomendações prescritas pelos fabricantes. O adesivo Cascophen foi preparado a partir da mistura de 100 partes de Cascophen para cada 20 partes de preparador endurecedor. Para o adesivo Cascorez não foi necessário o preparo do adesivo, pois este constitui um adesivo monocomponente, de cor branca, pronto para utilização.

\section{Métodos}

As vigas foram confeccionadas com sete ripas de bambu (numeradas de cima para baixo), apresentando seção transversal média de $2,88 \mathrm{~cm}$ de base por $4,99 \mathrm{~cm}$ de altura e $80,8 \mathrm{~cm}$ de comprimento. As vigas em BLC foram preparadas com quatro diferentes disposições dos nós e emendas de topo (A, B, C e D), conforme a Figura 3. A disposição "A" apresenta nós nas extremidades das ripas 1, 3, 5 e 7; e as emendas, nas ripas de números 2,4 e 6 . Na conformação "B" há nós nas extremidades das ripas 2, 4 e 6; e as emendas ocorreram nas ripas de números $1,3,5$ e 7. Já para o tipo " $C$ " não foram efetuadas emendas; em contrapartida, apresentam nós nas extremidades das ripas de números 2,4 e 6 ; e os nós ocorreram nos centros das ripas 1, 3, 5 e 7 . Finalmente, o tipo "D" apresenta nós nas extremidades e ausência de emendas em todas as ripas da viga.

Foram confeccionadas 15 vigas para realização do ensaio, das quais 8 foram fabricadas com adesivo Cascophen, duas vigas de cada um dos tipos "A", "B", "C" e "D", e 7 foram fabricadas com adesivo Cascorez, duas vigas de cada um dos tipos "A", "B" e "C", adicionadas de apenas uma do tipo "D".

Após a limpeza das ripas de bambu com escova de cerdas de nylon, o adesivo foi distribuído entre as ripas com o auxílio de hastes finas e pincel utilizando uma gramatura de $215,5 \mathrm{~g} / \mathrm{m}^{2}$. Para colagem, as ripas foram dispostas todas em uma mesma direção paralela às fibras de bambu e foram colocadas no dispositivo de prensagem sob uma pressão de 6,2 $\mathrm{MPa}$, controlada por meio das propriedades dos parafusos de prensagem (número de parafusos, tipo de rosca, passo do parafuso, diâmetro médio, número de voltas aplicadas na porca e coeficiente de atrito entre a rosca do parafuso e a porca). Na Figura 4a, apresenta-se o processo de união das ripas. Após a cura do adesivo, segundo recomendações dos fabricantes, retirava-se o BLC do equipamento de prensagem e efetuava-se o acabamento com o auxílio de serra circular e de plaina. Na Figura 4b, apresentam-se as vigas de BLC após o acabamento.

Objetivando-se a comparação entre as vigas de BLC e as vigas de madeira natural de reflorestamento, usualmente empregadas na construção civil, foram fabricadas 4 vigas de madeira serrada padrão com dimensões similares àquelas das vigas de BLC. Foram confeccionadas

18 Lima, D. M. de; Amorim, M. M.; Lima Júnior, H. C.; Barbosa, N. P.; Wilrich, F. L. 
2 vigas de Eucalyptus grandis (E1 e E2) e outras 2 de Araucaria angustifolia ou pinho-do-paraná (P1 e P2).

As vigas analisadas (biapoiadas isostáticas, com vão de 75,0 cm) foram ensaiadas à flexão por meio do ensaio de flexão de quatro pontos, sendo dois pontos de carregamento ativo nos terços médios, e dois reativos nos apoios extremos, conhecido como ensaio de Stuttgart (Figura 5a). As cargas foram aplicadas a uma velocidade média de $20 \mathrm{~N} / \mathrm{s}$, por meio de dois cilindros hidráulicos conectados, cada um, a uma célula de carga, com capacidade de $100 \mathrm{kN}$. Os deslocamentos centrais verticais (no meio do vão) foram obtidos através de medidores de deslocamento do tipo LVDT, com curso de $100 \mathrm{~mm}$ e sensibilidade de $0,01 \mathrm{~mm}$. As leituras foram realizadas por um sistema de aquisição de dados a $2,0 \mathrm{~Hz}$ e gravadas em um computador. Além disso, o ensaio foi realizado seguindo estágios de carregamento com incremento de carga igual a $200 \mathrm{~N}$ em cada um dos cilindros hidráulicos. Na Figura 5b, exibe-se uma das vigas de BLC preparada para o ensaio.

Figura 3 - Disposição das ripas e nós nas vigas de BLC (A, B, C e D)
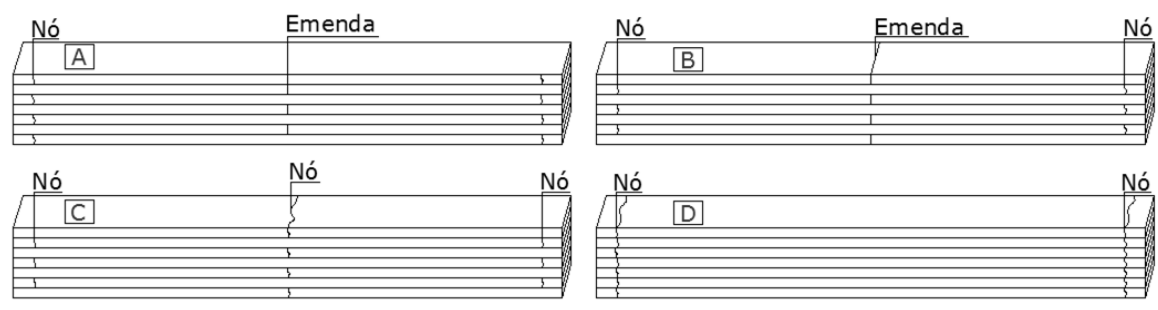

Figura 4 - Vigas de seção retangular em BLC

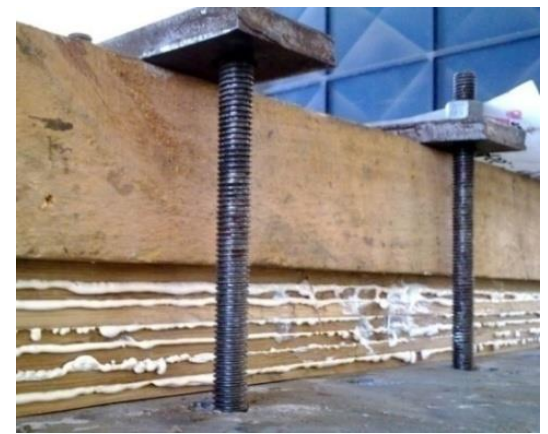

(a) Processo de colagem (Cascorez)

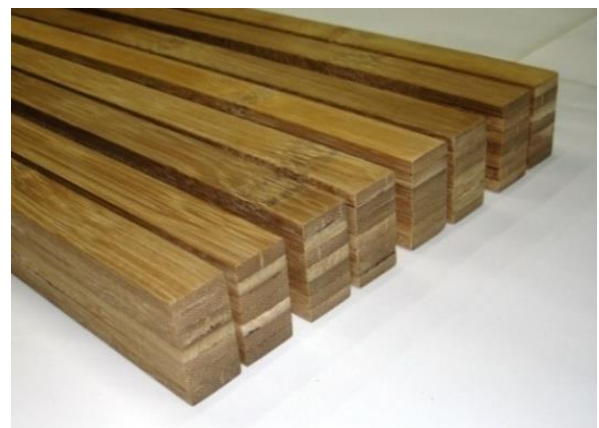

(b) Vigas acabadas (Cascophen)

Figura 5 - Detalhes do ensaio das vigas de seção retangular
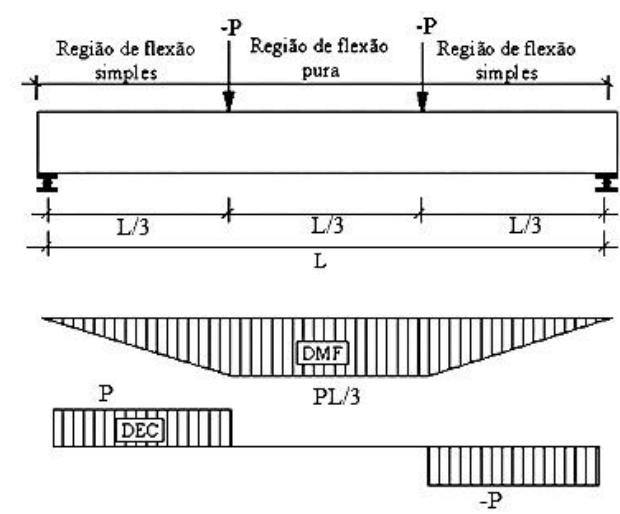

(a) Ensaio de Stuttgart

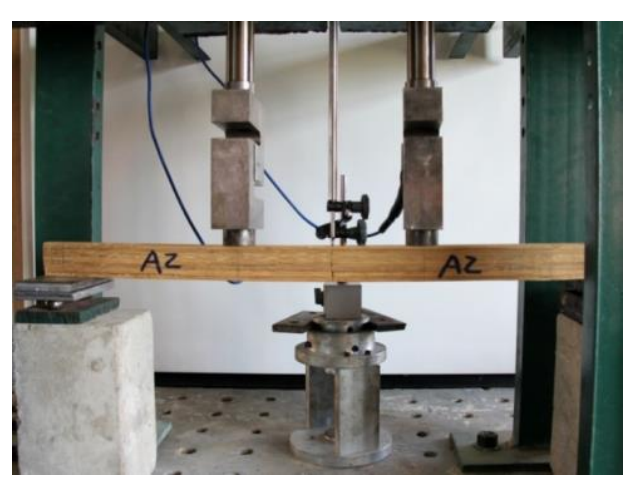

(b) Viga A2

Fonte: adaptado de Lima Júnior et al. (2005).

Nota: Legenda:

"DMF" diagrama de momento fletor; e

"DEC" diagrama de esforço cortante. 


\section{Resultados e discussão}

Nos ensaios de flexão das vigas de BLC verificouse que a metodologia de ensaio e leitura de dados mostrou-se adequada. Para as análises das vigas ensaiadas foram construídos gráficos carga vs. deslocamento (Figura 6), nos quais a carga adotada foi a média das duas cargas aplicadas, e o deslocamento central foi o deslocamento mensurado no meio do vão pelo LVDT. Observou-se comportamento praticamente linear até próximo da carga de ruptura para praticamente todas as vigas ensaiadas, tanto para as vigas de BLC (à base dos adesivos Cascorez e Cascophen) quanto para as vigas de madeiras $(E$. grandis e pinho-do-paraná). Adicionalmente, são consideradas válidas as hipóteses clássicas de flexão para o cálculo das tensões normais à flexão para todas as vigas ensaiadas (de BLC e de madeira).

$\mathrm{Na}$ Tabela 1, concatenam-se os principais dados das vigas ensaiadas (cargas de ruptura $\left[F_{M}\right]$, deslocamentos centrais verticais correspondentes (v), rigidez à flexão (EI) e forma de ruptura). Percebe-se que algumas das vigas ensaiadas não romperam efetivamente por mecanismos de flexão, uma vez que ocorreu ruptura por cisalhamento longitudinal (paralelo ao plano de colagem ou paralelo às fibras do bambu). Apesar disso, calculou-se a rigidez flexional para todas as vigas ensaiadas a partir da inclinação da reta secante à curva carga $\mathrm{x}$ deslocamento nos pontos de $50 \%$ e $10 \%$ da carga máxima de ensaio, conforme especificado pela norma para projeto de estruturas de madeira NBR 7190 (ABNT, 1997). Portanto, para um ensaio de flexão de quatro pontos, a rigidez à flexão é dada pela Equação 2:

$E I=\left(\frac{F_{M, 50 \%}-F_{M, 10 \%}}{v_{50 \%}-v_{10 \%}}\right) \cdot \frac{23 L^{3}}{648}$

Eq. 2

Na qual $E I$ é a rigidez à flexão; $F_{M, 10 \%}$ e $F_{M, 50 \%}$ são as cargas referentes a $10 \%$ e $50 \%$ da carga máxima de ensaio respectivamente; $v_{10 \%}$ e $v_{50 \%}$ são os deslocamentos no ponto médio do vão referentes a $10 \%$ e $50 \%$ da carga máxima; e $L$ é o vão entre apoios.

Na Figura 6 apresentam-se os resultados de carga máxima e rigidez à flexão das vigas de BLC.

As forças de ruptura das vigas de BLC (A, B, C e D) coladas com adesivo Cascophen apresentaram- se superiores às das coladas com adesivo Cascorez. Os modos de ruptura do adesivo Cascorez foram causados por cisalhamento paralelo ao plano de colagem, para todas as vigas desse adesivo. Para as vigas fabricadas com adesivo Cascophen, o colapso variou entre rupturas das ripas devidas às tensões normais de flexão e ruptura por cisalhamento paralelo ao plano de colagem e às fibras do bambu.

As vigas do tipo " $\mathrm{B}$ " com emendas centrais nas ripas externas $\left(1^{\mathrm{a}}\right.$ e $\left.7^{\mathrm{a}}\right)$ e nas intercaladas $\left(3^{\mathrm{a}}\right.$ e $\left.5^{\mathrm{a}}\right)$ apresentaram as menores cargas de ruptura e menor rigidez à flexão, em função da diminuição da inércia nessa região. Nessas vigas inicialmente ocorreu o desprendimento das lâminas externas e, consequentemente, com o aumento das cargas, a ruptura por tração na $6^{\mathbf{a}}$ ripa para as vigas Cascophen, e por cisalhamento paralelo ao plano de colagem para as vigas Cascorez.

As vigas do tipo A_CASCOREZ apresentaram rigidezes superiores às vigas do tipo C_CASCOREZ, que, por sua vez, são mais rígidas do que as vigas tipo D_CASCOREZ. Em termos de capacidade de carga, estas são ordenadas da maior para menor da seguinte forma: A_CASCOREZ, D_CASCOREZ e C_CASCOREZ.

As vigas do tipo A_CASCOPHEN apresentaram rigidezes e capacidades de carga superiores às vigas do tipo B_CASCOPHEN, sendo inferiores às vigas do tipo C_CASCOREZ. As vigas do tipo D_CASCOPHEN apresentaram os resultados mais elevados, porém com rupturas ocorrendo por cisalhamento paralelo às fibras, o que limitou a capacidade de carga das vigas, pois não apresentaram ruptura por compressão e/ou tração paralelas às fibras. Tal fato indica que a resistência ao cisalhamento paralelo às fibras do bambu é um fator limitador à capacidade resistente das vigas.

As vigas de madeira natural de pinho-do-paraná apresentaram rigidezes e cargas de ruptura semelhantes às vigas de BLC do tipo B_CASCOPHEN. Em relação às vigas de $E$. grandis, estas mostraram um comportamento similar ao das vigas de BLC do tipo A_CASCOPHEN em termos de rigidez e de cargas de ruptura. 
Figura 6 - Curvas carga $\mathrm{x}$ deslocamento das vigas

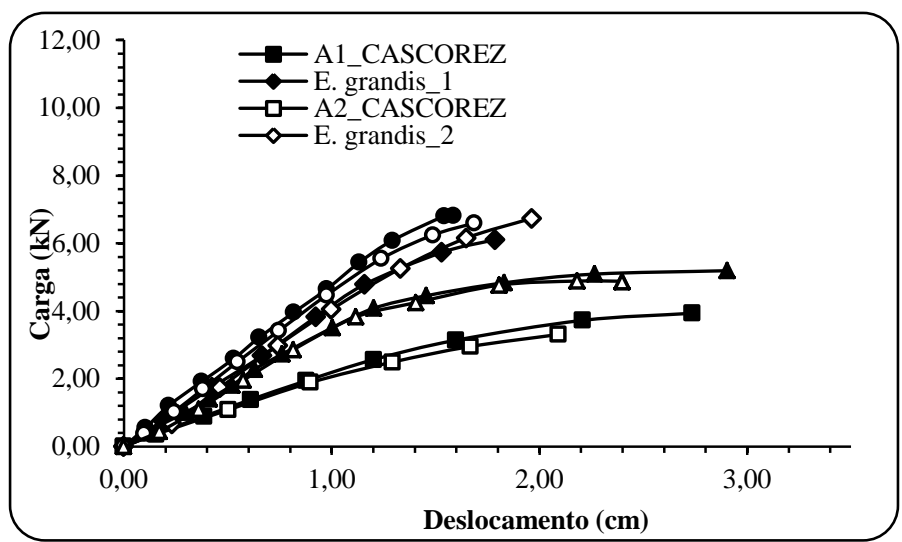

(a) Vigas do tipo "A"

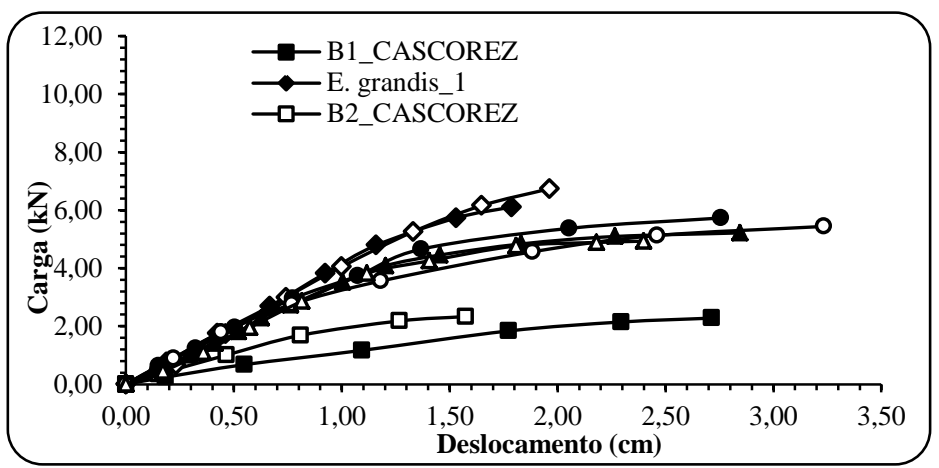

(b) Vigas do tipo "B"

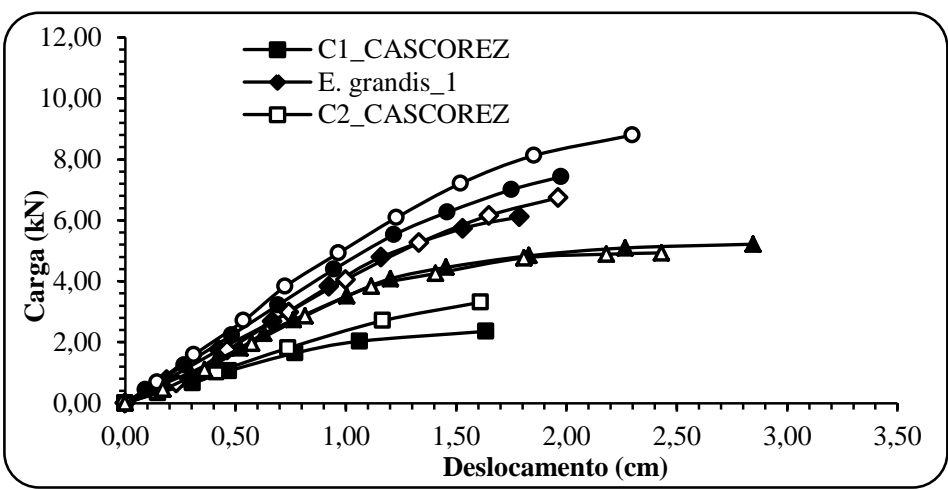

(c) Vigas do tipo "C"

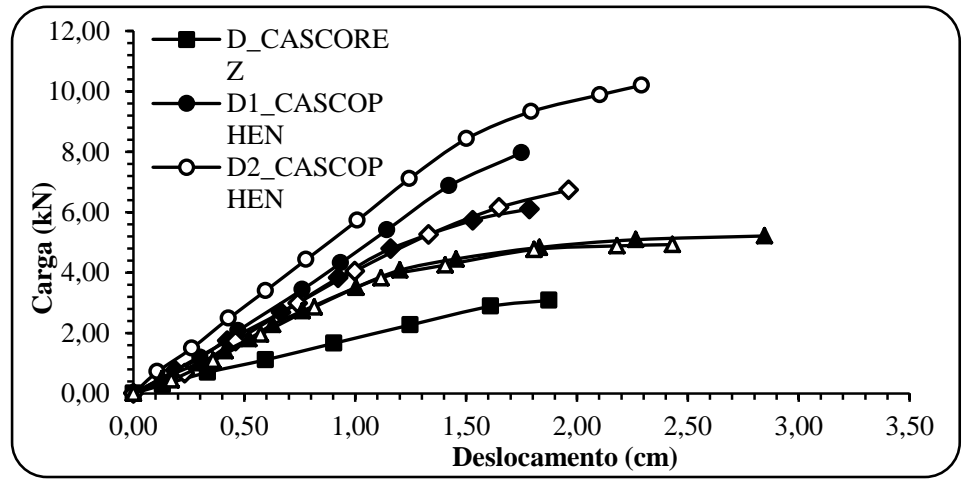

(d) Vigas do tipo "D" 
Tabela 1 - Comportamento das vigas: carga, deslocamento, rigidez e forma de ruptura

\begin{tabular}{|c|c|c|c|c|}
\hline Vigas & $\begin{array}{c}\text { Carga } \\
\text { máxima } \\
\mathrm{F}_{\mathrm{M}}(\mathbf{k N})\end{array}$ & $\begin{array}{l}\text { Deslocamento } \\
\text { central } v(\mathrm{~cm})\end{array}$ & 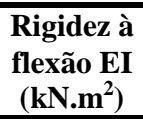 & Modo de ruptura \\
\hline \multicolumn{5}{|c|}{ Vigas de BLC com adesivo Cascorez } \\
\hline A1 & 3,94 & 2,74 & 4,81 & $\begin{array}{c}\text { Compressão das fibras superiores e cisalhamento no } \\
\text { adesivo entre a } 4^{\mathrm{a}} \text { e a } 5^{\mathrm{a}} \text { ripas. }\end{array}$ \\
\hline $\mathrm{A} 2$ & 3,31 & 2,08 & 3,15 & Cisalhamento entre a $3^{\mathrm{a}}$ e a $4^{\mathrm{a}}$ ripas. \\
\hline B1 & 2,28 & 2,71 & 1,51 & $\begin{array}{l}\text { Ruptura na emenda da ripa inferior ( } 7^{\mathrm{a}} \text { ripa) devido ao } \\
\text { descolamento dela. Cisalhamento no adesivo entre a } 3^{\mathrm{a}} \\
\text { e a } 4^{\mathrm{a}} \text { ripas. }\end{array}$ \\
\hline $\mathrm{B} 2$ & 2,33 & 1,57 & 3,28 & $\begin{array}{c}\text { Ruptura na emenda da ripa inferior ( } 7^{\text {a }} \text { ripa) devido ao } \\
\text { descolamento dela. Cisalhamento no adesivo entre a } 3^{\text {a }} \\
\text { e a } 4^{\mathrm{a}} \text { ripas e entre a } 5^{\mathrm{a}} \text { e a } 6^{\mathrm{a}} \text { ripas. }\end{array}$ \\
\hline $\mathrm{C} 1$ & 2,36 & 1,64 & 3,33 & $\begin{array}{l}\text { Cisalhamento no adesivo entre a } 4^{a} \text { e a } 5^{a} \text { ripas e entre a } \\
5^{a} \text { e } 6^{a} \text { ripas. }\end{array}$ \\
\hline $\mathrm{C} 2$ & 3,31 & 1,61 & 3,21 & Cisalhamento no adesivo entre a $4^{\mathrm{a}}$ e a $5^{\mathrm{a}}$ ripas. \\
\hline $\mathrm{D}$ & 3,08 & 1,87 & 2,57 & $\begin{array}{l}\text { Cisalhamento no adesivo entre a } 3^{\mathrm{a}} \text { e a } 4^{\mathrm{a}} \text { ripas e entre a } \\
5^{\mathrm{a}} \text { e a } 4^{\mathrm{a}} \text { ripas. }\end{array}$ \\
\hline \multicolumn{5}{|c|}{ Vigas de BLC com adesivo Cascophen } \\
\hline A1 & 6,87 & 1,57 & 7,33 & Cisalhamento paralelo às fibras do bambu na $5^{\text {a }}$ ripa. \\
\hline $\mathrm{A} 2$ & 6,60 & 1,69 & 7,14 & Tração junto ao nó da lâmina inferior ( $7^{\mathrm{a}}$ ripa). \\
\hline $\mathrm{B} 1$ & 5,73 & 2,76 & 5,82 & Ruptura na emenda da ripa inferior ( $7^{\mathrm{a}}$ ripa) com \\
\hline $\mathrm{B} 2$ & 5,37 & 3,23 & 5,30 & posterior ruptura por tração na $6^{\mathrm{a}}$ ripa. \\
\hline $\mathrm{C} 1$ & 7,43 & 1,98 & 7,20 & Ruptura por tração no nó central da ripa inferior \\
\hline $\mathrm{C} 2$ & 8,79 & 2,30 & 7,72 & ( $7^{\mathrm{a}}$ ripa). \\
\hline D1 & 7,97 & 1,75 & 7,22 & Cicolbomento nololò fibro di hombu n 5a rino \\
\hline D2 & 10,21 & 2,29 & 8,37 & Cisalhamento paralelo às fibras do bambu na $5^{a}$ ripa. \\
\hline \multicolumn{5}{|c|}{ Vigas de madeira Eucalyptus grandis } \\
\hline E1 & 6,11 & 1,79 & 6,03 & Compressão das fibras superiores e consequente ruptura \\
\hline E2 & 6,74 & 1,96 & 6,65 & das fibras inferiores por tração. \\
\hline \multicolumn{5}{|c|}{ Vigas de madeira pinho-do-paraná } \\
\hline P1 & 5,22 & 2,85 & 5,34 & Compressão das fibras superiores e consequente ruptura \\
\hline $\mathrm{P} 2$ & 4,93 & 2,43 & 5,98 & das fibras inferiores por tração. \\
\hline
\end{tabular}

22 Lima, D. M. de; Amorim, M. M.; Lima Júnior, H. C.; Barbosa, N. P.; Wilrich, F. L. 
Figura 7 - Gráficos de comparação dos resultados de capacidade de carga e rigidez das vigas ensaiadas
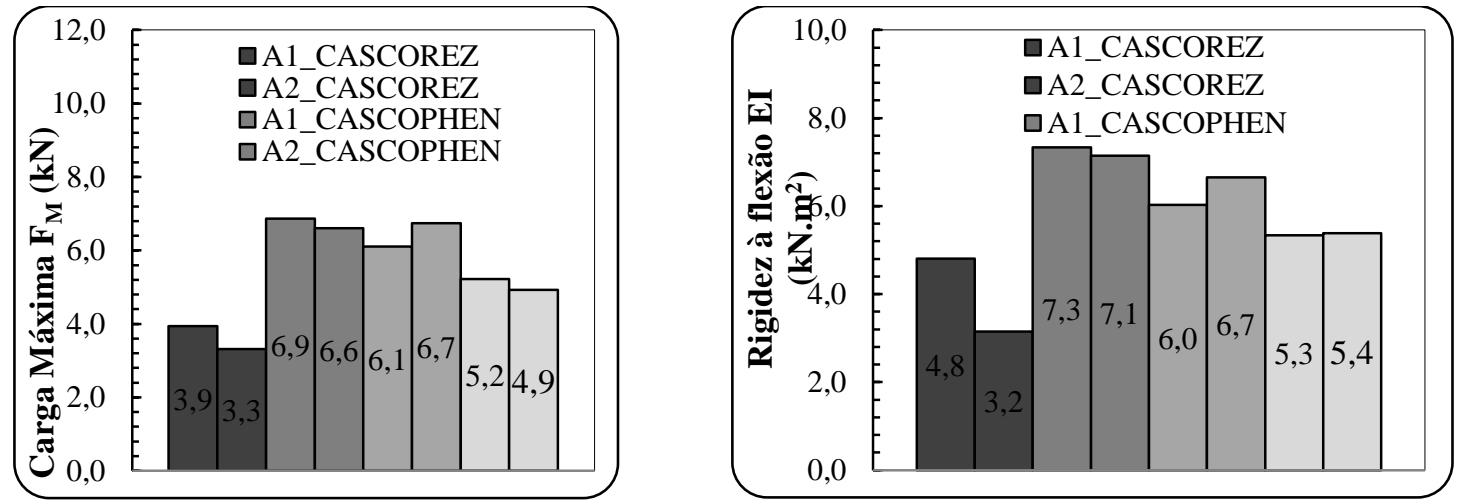

(a) Vigas do tipo "A"
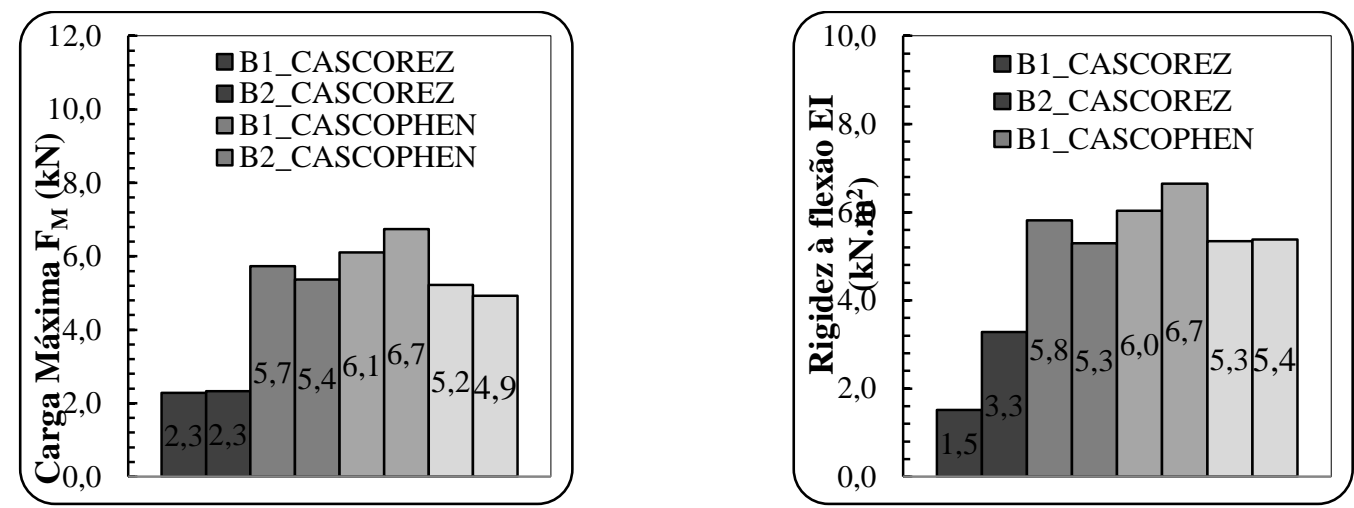

(b) Vigas do tipo "B"
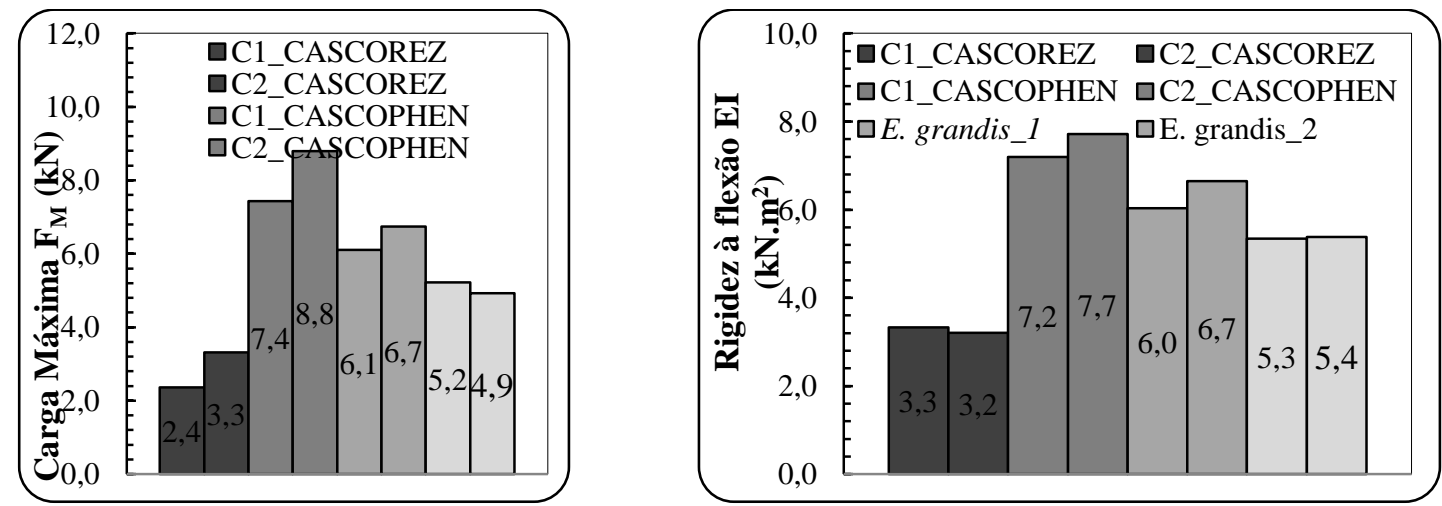

(c) Vigas do tipo "C"
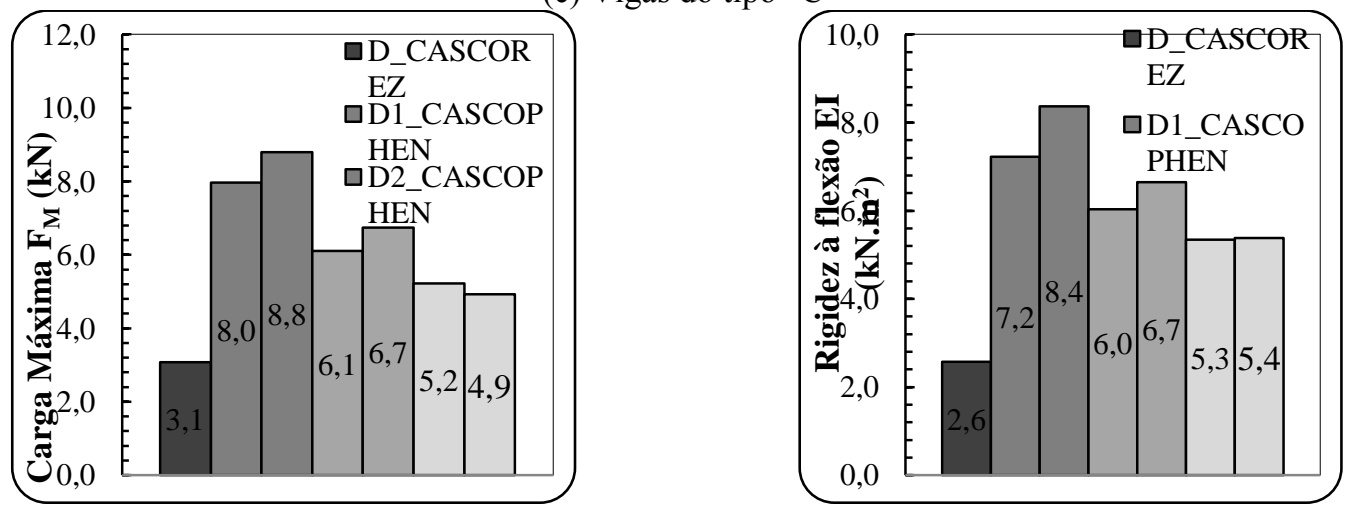

(d) Vigas do tipo "D" 
Segundo o modo de ruptura, a viga A1_CASCOREZ apresentou uma tensão normal de compressão máxima igual a $125,82 \mathrm{MPa}$ (Figura 8a); salienta-se que as vigas do tipo "A" contribuem com apenas 4 ripas, das 7 que compõem a viga, para o cálculo do momento de inércia em relação à linha neutra do elemento fletido, uma vez que foram realizadas emendas de topo (Equação 1). Para as mesmas condições, a tensão de cisalhamento máxima, entre a $4^{\mathrm{a}}$ e a

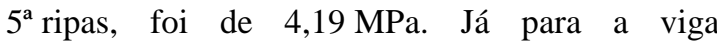
A2_CASCOREZ, a tensão de cisalhamento máxima, entre a $3^{\mathrm{a}}$ e a $4^{\mathrm{a}}$ ripas, foi de $3,55 \mathrm{MPa}$ (Figura 8b). Adicionalmente, a tensão de cisalhamento máxima paralela às fibras do bambu na $5^{\mathrm{a}}$ ripa da viga A1_CASCOPHEN resultou igual a 6,40 MPa. Na Figura 9, apresenta-se uma viga do tipo "A" fletida durante o ensaio.

As vigas B1_CASCOREZ e B2_CASCOREZ romperam por cisalhamento, entre a $3^{\mathrm{a}}$ e a $4^{\mathrm{a}}$ ripas, após ocorrer descolamento da ripa inferior (Figura 10), e apresentaram uma tensão de cisalhamento máxima de 2,69 MPa e 2,98 MPa respectivamente. Ambas as vigas B_CASCOPHEN romperam por tração na $6^{\mathrm{a}}$ ripa após ocorrer descolamento da ripa inferior com uma tensão normal de tração máxima igual a 200,51 MPa e 187,91 MPa para as vigas B1 e B2 respectivamente.

A ruptura das vigas C1_CASCOREZ e C2_CASCOREZ ocorreram, similarmente às vigas do tipo "B", por cisalhamento no adesivo com uma tensão máxima de cisalhamento igual a 2,36 MPa e $3,25 \mathrm{MPa}$ respectivamente. Para as vigas

Figura 8 - Modos de ruptura das vigas do tipo "A"

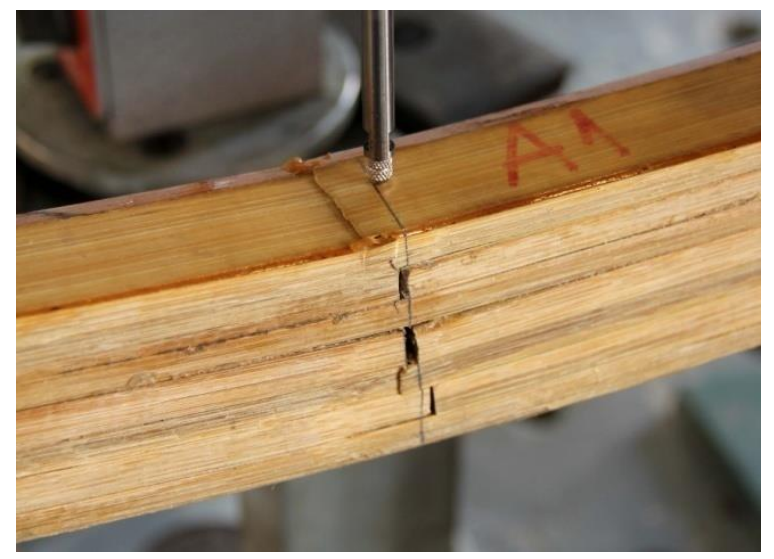

(a) Compressão da fibra superior
C1_CASCOPHEN e C2_CASCOPHEN, observou-se ruptura por tração na flexão na $7^{\mathrm{a}}$ ripa com os seguintes valores de tensões normais de tração máximos: $199,27 \mathrm{MPa}$ e $235,74 \mathrm{MPa}$ respectivamente.

A tensão máxima de cisalhamento longitudinal na viga D_CASCOREZ foi de 3,14 MPa. Além disso, observou-se ruptura na região ocupada por um nó de bambu que se encontrava diretamente abaixo da carga aplicada (Figura 11). Ambas as vigas do tipo "D" fabricadas com adesivo Cascophen tiveram uma ruptura por cisalhamento paralelo às fibras do bambu na $5^{\text {a }}$ ripa; dessa forma, as tensões máximas de cisalhamento para as vigas D1_CASCOPHEN e D2_CASCOPHEN foram de 7,42 $\mathrm{MPa}$ e 9,51 $\mathrm{MPa}$ respectivamente.

As duas vigas de madeira E. grandis romperam por tração nas fibras inferiores (Figura 12) com as seguintes tensões máximas de tração: $121,50 \mathrm{MPa}$ e 134,03 MPa. Por fim, as vigas de madeira pinhodo-paraná romperam por tração na flexão (Figura 12), apresentando tensões normais máximas das vigas P1 e P2 iguais a 103,81 $\mathrm{MPa}$ e $98,04 \mathrm{MPa}$ respectivamente.

\section{Considerações finais}

Os gráficos "carga x deslocamento" das vigas ensaiadas apresentaram comportamento linear até próximo da carga de ruptura, tanto para as vigas de BLC quanto para as vigas de madeira (E. grandis e pinho-do-paraná).

24 Lima, D. M. de; Amorim, M. M.; Lima Júnior, H. C.; Barbosa, N. P.; Wilrich, F. L. 
Figura 9 - Ensaio de uma das vigas do tipo "A"

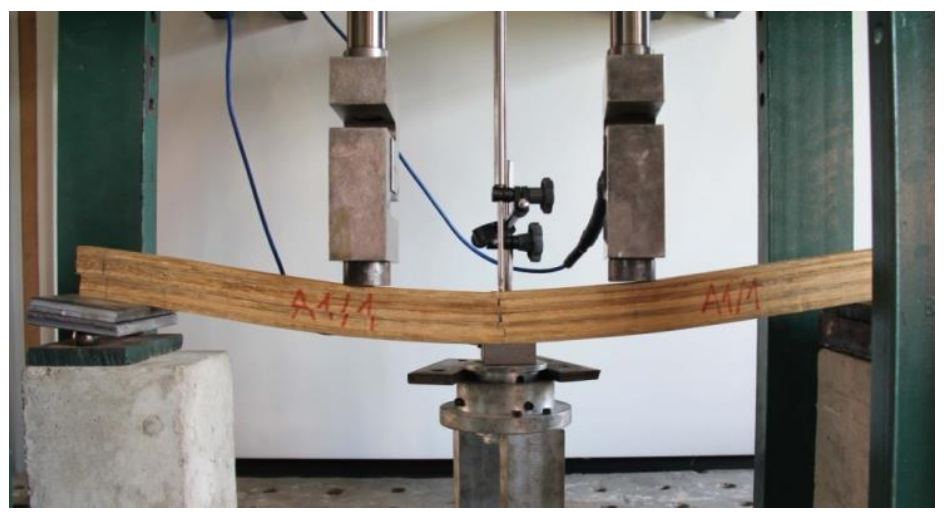

Figura 10 - Modos de ruptura das vigas do tipo “B”

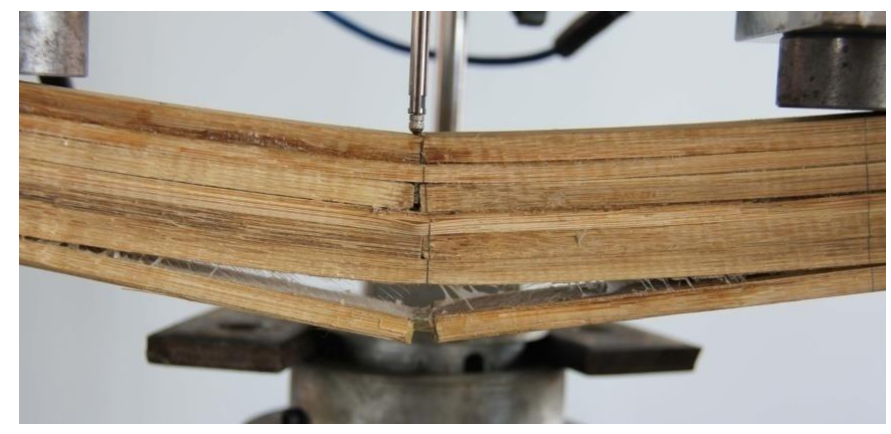

(a) Descolamento da ripa inferior

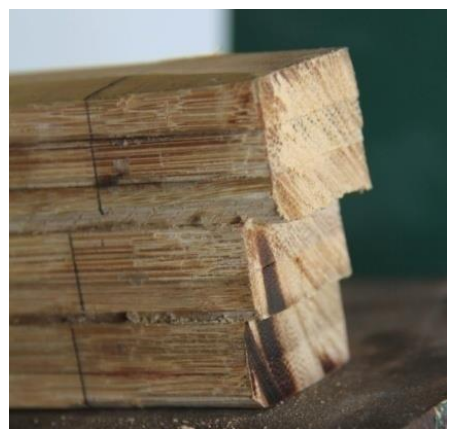

(b) Deslocamento horizontal relativo em planos de colagem

Figura 11 - Ruptura do nó de bambu da viga D_CASCOREZ

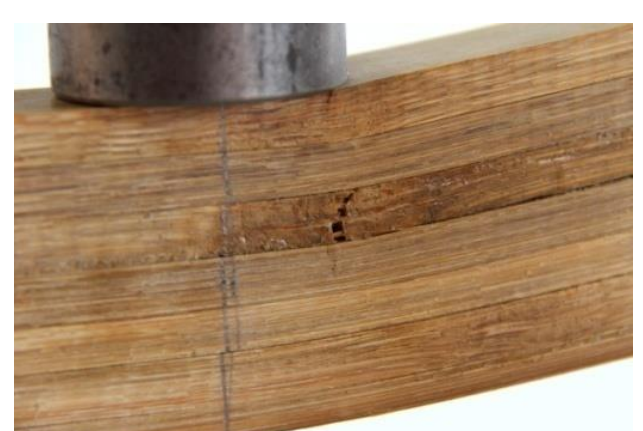

(a) Vista

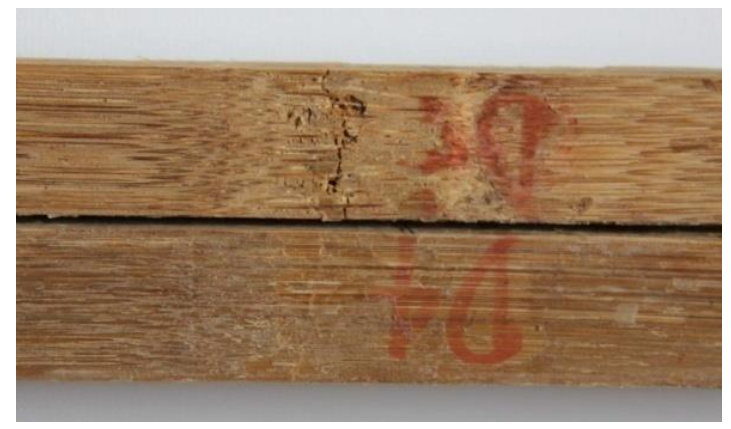

(b) Após a abertura da viga

Figura 12 - Ruptura por tração nas vigas de madeira

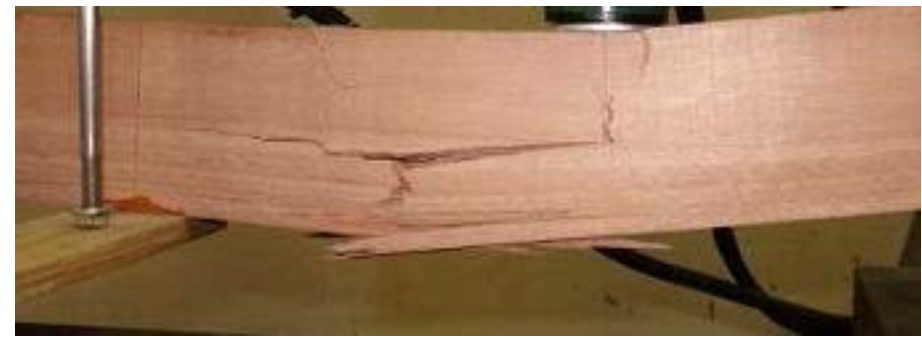


As cargas de ruptura das vigas de BLC (A, B, C e D) coladas com adesivo Cascophen apresentaramse superiores às coladas com adesivo Cascorez. Além disso, todas as vigas Cascorez romperam por fluxo de cisalhamento no plano de colagem, enquanto as vigas Cascophen apresentaram modos de rupturas diferenciados em função do tipo de viga ensaiada. Evidencia-se atenção especial para o projeto de estruturas de BLC quanto ao modo de ruptura por cisalhamento, tanto o cisalhamento paralelo às fibras do bambu, quanto o cisalhamento no plano de colagem. Portanto, devem-se levar em consideração os ensaios de cisalhamento puro, paralelo às fibras do bambu e ao plano de colagem dos adesivos (Cascorez e Cascophen) realizados por Lima (2013).

A rigidez e a capacidade de cargas das vigas de BLC variaram de acordo com a disposição de nós e emendas. As vigas do tipo "B" apresentaram as menores cargas de ruptura e menor rigidez à flexão. As vigas do tipo D_CASCOPHEN apresentaram os resultados mais elevados, porém romperam por fluxo de cisalhamento paralelo às fibras. Isso indica que a resistência ao cisalhamento paralelo às fibras do bambu é um fator limitador à capacidade resistente das vigas BLC. O comportamento das vigas de madeira natural de pinho-do-paraná, em termos de rigidez e cargas de ruptura, foi semelhante ao das vigas de BLC do tipo B_CASCOPHEN. Em relação às vigas de E. grandis, estas se mostraram com comportamento aproximado ao das vigas de BLC do tipo A_CASCOPHEN.

De acordo com as análises realizadas e os critérios estabelecidos pela NBR 7190 (ABNT, 1997), as vigas fabricadas com BLC podem ser dimensionadas conforme o referido código normativo.

\section{Referências}

\section{ASSOCIAÇÃO BRASILEIRA DE NORMAS}

TÉCNICAS. NBR 7190: projetos de estruturas de madeira. Rio de Janeiro, 1997. 107 p.

BONO, C. T. Madeira Laminada Colada na

Arquitetura: sistematização de obras executadas no Brasil. São Paulo, 1996. 365 f. Dissertação (Mestrado em Engenharia Civil) - Escola de Engenharia, Universidade de São Paulo, São Paulo, 1996.
LIMA, D. M. de. Bambu Laminado Colado (Dendrocalamus giganteus) Aplicado à Treliça Plana Tipo Howe e à Viga Retangular. Recife, 2013. 234 f. Dissertação (Mestrado em Engenharia Civil e Ambiental) - Programa de Pós-Graduação em Engenharia Civil e Ambiental, Universidade Federal de Pernambuco, Recife, 2013.

LIMA JÚNIOR, H. C.; DIAS, A. A. Vigas Mistas de Madeira de Reflorestamento e Bambú Lâminado Colado: análise teórica e experimental. Revista Brasileira de Engenharia Agrícola e Ambiental, Campina Grande, v. 5, n. 3, p. 519 524, 2001.

LIMA JÚNIOR, H. C. et al. Vigas de Concreto Reforçadas com Bambú Dendrocalamus giganteus I: análise experimental. Revista Brasileira de Engenharia Agrícola e Ambiental, Campina Grande, v. 9, n. 4, p. 642-651, 2005.

MESQUITA, L. P. et al. Determinação da Tensão de Aderência de Cálculo Bambú-Concreto.

Revista Brasileira de Engenharia Agrícola e Ambiental, Campina Grande, v. 10, n. 2, p. 505516, 2006.

PEREIRA, M. A. dos R.; BERALDO, A. L. Bambú de Corpo e Alma. Bauru: Canal6, 2008. $240 \mathrm{p}$.

PFEIL, W.; PFEIL, M. Estruturas de Madeira. 6. ed. Rio de Janeiro: Livros Técnicos e Científicos, 2003. 224 p.

\section{Agradecimentos}

Ao Laboratório de Modelos Reduzidos da Universidade Estadual do Oeste do Paraná (Unioeste), pela doação do bambu utilizado neste trabalho.

Ao Laboratório de Sistemas Construtivos (LSC) do Centro Acadêmico do Agreste (CAA), da Universidade Federal de Pernambuco (UFPE), onde foram realizados os ensaios desta pesquisa.

À Fundação de Amparo à Ciência e Tecnologia do Estado de Pernambuco (Facepe), pela concessão da bolsa de mestrado ao primeiro autor. 


\section{Douglas Mateus de Lima}

Núcle de Tecnologia, Centro Acadêmico do Agreste | Universidade Federal de Pernambuco | Rodovia BR 104, km 59, Sítio Juriti, Campus do Agreste, Nova Caruaru | Caruaru - PE - Brasil | CEP 55002-970 | Tel.: (81) 2126-7771 | E-mail: douglasortoedro@gmail.com

\section{Mariana Mendes Amorim}

Núcle de Tecnologia, Centro Acadêmico do Agreste | Universidade Federal de Pernambuco | Email: amorim.mariana@gmail.com

\section{Humberto Correia Lima Júnior}

Núcle de Tecnologia, Centro Acadêmico do Agreste | Universidade Federal de Pernambuco | Email: humbertolima@ufpe.br

\section{Normando Perazzo Barbosa}

Centro de Tecnologia | Universidade Federal da Paraíba | Campus I, Cidade Universitária LABEME, Castelo Branco | João Pessoa - PB Brasil | CEP 58051-900 | Tel.: (83) 3216-7910 | E-mail: nperazzob@yahoo.com.br

\section{Fábio Luiz Wilrich}

ITAIPU Binacional | Av. Tancredo Neves 6731, CP 1555 | Foz do Iguaçu - PR Brasil | CEP 85856-000 | Tel: (45) 520-6220 |

Email: miriamfabio@gmail.com

\section{Revista Ambiente Construído}

Associação Nacional de Tecnologia do Ambiente Construído

Av. Osvaldo Aranha, $99-3^{\circ}$ andar, Centro

Porto Alegre - RS - Brasil

CEP $90035-190$

Telefone: +55 (51) 3308-4084

Fax: +55 (51) 3308-4054

www.seer.ufrgs.br/ambienteconstruido

E-mail: ambienteconstruido@ufrgs.br 